\title{
DNA testing for parentage verification in a conservation nucleus of Pantaneiro horse
}

\author{
Fabiana Tavares Pires de Souza Sereno ${ }^{1}$, José Robson Bezerra Sereno ${ }^{2}$, Jose Luis Vega-Pla ${ }^{3}$ \\ and Juan Vicente Delgado ${ }^{4}$ \\ ${ }^{I}$ Faculdade de Agronomia e Medicina Veterinária, Universidade de Brasília, Brasília, DF, Brazil. \\ ${ }^{2}$ Embrapa Cerrados, Planaltina, DF, Brazil. \\ ${ }^{3}$ Laboratorio de Genética Molecular, Servicio de Cría Caballar y Remonta, Córdoba, España. \\ ${ }^{4}$ Departamento de Genética, Facultad de Veterinária, Universidad de Córdoba, Córdoba, España.
}

\begin{abstract}
We investigated the genealogy of the in situ conservation nucleus of the Pantaneiro horse using DNA microsatellites by evaluating 101 horses, the group consisting of 71 adult horses ( 3 stallions, 40 male and 31 mares) and 27 foals (14 colts and 13 fillies). Genomic DNA was extracted from hair roots and genotyped using 12 microsatellite markers (AHT4, AHT5, ASB2, ASB17, ASB23, HMS3 HMS6, HMS7, HTG4, HTG10, LEX33 and VHL20). The number of alleles per locus varied from 6 to 13 , with a mean of 7.8 and the expected heterozygosity ranged from 0.544 to 0.734 (mean 0.644). The VLH20, ASB2, HTG10, ASB23 markers had a high (>0.8) polymorphism information content and the total exclusion probability of the 12 microsatellite loci was 0.99 . The genealogical study of the Pantaneiro horse using genetic markers was efficient in detecting mistakes during paternity and maternity designation and is an important tool which can be used together with traditional systems of animal identification. The use of genetic markers is recommended in the systematic control of the genealogical registrations and conservation plans to improve genetic aspects of the Pantaneiro horse.
\end{abstract}

Key words: Pantaneiro horse, animal conservation, microsatellites, markers, parentage verification.

Received: November 28, 2006; Accepted: June 26, 2007.

The Pantaneiro horse is well adapted to the climatic conditions of the Brazilian Pantanal, a marshy region in central western Brazil in the states of Mato Grosso and Mato Grosso do Sul to which this horse is restricted. Spanish and Portuguese colonizers introduced equines into Brazil from the Iberian Peninsula, with horses arriving from Central America, across the Andes from Peru, from Northern Argentina, from Argentina or Paraguay through the Jesuit missions and directly from the Iberian Peninsula with horses imported from the Spanish region of Andalusia (Dowdall, 1982). Preservation and expansion of the Pantaneiro horse in the Brazilian Pantanal has been centered on its ability to deal with cattle and the adaptation of this breed to the Pantanal environment, this breed being preferred by farmers and ranchers in the region because it is hardy and supports the long-distance cattle drives necessary for transporting the cattle in this marshy region.

Microsatellites have been used for parentage testing and individual identification in forensic science because

Send correspondence to Fabiana T.P.S. Sereno. Faculdade de Agronomia e Medicina Veterinária, Universidade de Brasília, SQN 115, Bloco G, apto 201, Asa Norte, 70772-070 Brasília, DF, Brazil. E-mail: fabiana_sereno@yahoo.com.br. they are highly polymorphic and show abundant sequences dispersed throughout most eukaryotic nuclear genomes (Tautz et al., 1986). Microsatellites have simple and stable inheritance when transmitted between generations and are controlled only by heredity. Furthermore, due to their small size they are efficiently amplified using the polymerase chain reaction. Many microsatellites are informative due to their high polymorphism and are useful in the paternity testing of horses (Marklund et al., 1994; Binns et al., 1995; Usha et al., 1995; Bowling et al., 1997; Tozaki et al., 2001; Cho and Cho, 2004; Lee and Cho, 2006).

Our study used 12 microsatellite markers for routine DNA typing for individual identification and parentage verification of Pantaneiro horses and calculated the number of alleles (A), mean observed and expected heterozygosity ( $H_{o}$ and $H_{e}$ respectively), polymorphic information content (PIC) and probability of exclusion (PE).

We evaluated a group of 101 Pantaneiro horses, 74 adults ( 3 stallions, 40 males and 31 mares) and 27 foals (14 colts and 13 fillies) from the nucleus at the Brazilian Agricultural Research Corporation (Empresa Brasileira de Agropecuária - Embrapa) Nhumirim Experimental Field Station, Embrapa Pantanal, Corumbá, Mato Grosso do Sul, 
Brazil. Samples of horse populations of the Pantaneiro breed DNA genome were prepared from hair roots.

Hair samples were taken from each of the horses and DNA extracted from hair roots using a previously published technique (Kawasaki, 1990). The following 12 microsatellites were selected for this study: VHL20 (Van Haeringen et al., 1994); AHT4 and AHT5 (Binns et al., 1995); ASB2 and ASB17 (Breen et al., 1997); ASB23 (Lear et al., 1999); HMS3, HMS6 and HMS7 (Guerín et al., 1994); HTG4 (Ellegren et al., 1992); HTG10 (Marklund et al., 1994); and LEX33 (Shiue et al., 1999). These markers are recommended for the individual identification and parentage verification of horses by the International Society for Animal Genetics (ISAG) Equine Genetics Parentage Testing Standardization Committee (EGPTSC).

Polymerase chain reaction genotyping of the 12 microsatellite was performed in a final volume of $15 \mu \mathrm{L}$ containing $10 \mathrm{ng}$ of genomic DNA, $10 \mathrm{X}$ PCR buffer, $1 \mu \mathrm{L}$ $\mathrm{ClMg}_{2}(50 \mathrm{mM}), 0.2 \mu \mathrm{L}$ of each dNTP $(25 \mathrm{mM}), 5 \mu \mathrm{L}$ primer and 0.2 of Taq DNA polymerase (ECOGEN, Spain). Amplification was carried out using two multiplex reactions (M1 and M2) using fluorochromes of similar-sized microsatellites $(\mathrm{M} 1=\mathrm{ATH} 4, \mathrm{AHT} 5, \mathrm{ASB} 17$, ASB23, HMS6, HMS7, HTG4 and VHL20; M2 = HMS3, ASB2, HTG10 and LEX33) and a PTC 100 thermocycler (MJ Research Inc, USA) using initial denaturation for 4 min at $95^{\circ} \mathrm{C}$, followed by 30 cycles of $95^{\circ} \mathrm{C}$ for $45 \mathrm{~s}$, $56-60{ }^{\circ} \mathrm{C}$ for $45 \mathrm{~s}$ and $75^{\circ} \mathrm{C}$ for $1 \mathrm{~min}$ with a final extension for $10 \mathrm{~min}$ at $72^{\circ} \mathrm{C}$. Amplified fragments were separated by electrophoresis on $6 \%(\mathrm{w} / \mathrm{v})$ polyacrylamide gel in an $\mathrm{ABI}$ 377XL automatic sequencer and the gels read using the Genescan Analysis v3.2.1 program (Applied Biosystems, Foster City, CA, USA) and the products denatured with formamide and electrophoresed in an ABI 377XL Genetic Analyzer using the recommended protocols. Size analyses of DNA fragments were performed separately with the Genotyper v2.5 program (Applied Biosystems, USA) and an internal size standard was used for sizing alleles (Genescan Size Standard HD-400, Applied Biosystems, USA). The DNA analysis was carried out by at the laboratory of one of the authors (Laboratório de Genética Molecular del Servicio de Cría Caballar y Remonta, Córdoba, Spain). Allelic frequencies and the number of alleles per locus were estimated by direct counting from observed genotypes. Heterozygosity was computed using the Tools for Population Genetic Analysis (TFPGA) program v1.3 (Miller, 1997). The PIC index was calculated using Microsoft ${ }^{\circledR}$ EXCEL $^{\circledR}$ (Botstein et al., 1980) and PE values were computed according to Huguet et al., 1988. Parentage testing was performed according to Mendelian rules.

The microsatellites used were highly polymorphic in the Pantaneiro horse (Table 1 and 2), with the average number of alleles per locus being 7.8 and varying from 3 for HMS1 to 9 for ASB17 (Table 1). We found that the mean $H_{o}$ was 0.78 and ranged from 0.694 to 0.863 while the mean $H_{e}$ was 0.644 and varied from 0.544 to 0.68 (Table 2). In our system, the mean PIC was 0.75 and varied from 0.68 for the HTG4 locus to 0.83 for the HTG10 locus (Table 2), and

Table 1 - Allele frequencies of microsatellite DNA polymorphisms in a sample of Pantaneiro horses.

\begin{tabular}{|c|c|c|c|c|c|c|c|c|c|c|c|c|}
\hline \multirow[b]{2}{*}{ Alleles } & \multicolumn{12}{|c|}{ Microsatellite loci } \\
\hline & HTG4 & HMS7 & HMS6 & AHT5 & AHT4 & VHL20 & HTG10 & HMS3 & ASB23 & LEX33 & ASB17 & ASB2 \\
\hline B & & & & & & & & & & & & 0.045 \\
\hline $\mathrm{C}$ & & & & & & & & & & & & 0.020 \\
\hline $\mathrm{F}$ & & & & & & & & & & & 0.030 & \\
\hline G & & & & & & & & & & 0.054 & 0.025 & \\
\hline $\mathrm{H}$ & & & & & 0.307 & & & & & & 0.035 & \\
\hline I & & & & 0 & 0.119 & 0.106 & 0.025 & 0.099 & 0.163 & & 0.064 & 0.119 \\
\hline $\mathrm{J}$ & & 0 & & 0.084 & 0.069 & & & & 0.307 & & 0 & 0 \\
\hline K & 0.069 & 0.005 & 0.059 & 0.143 & 0.168 & 0.066 & 0.030 & & 0.109 & 0.114 & 0.044 & 0.089 \\
\hline $\mathrm{L}$ & 0.178 & 0.360 & 0.134 & 0.040 & 0.040 & 0.131 & 0.084 & 0 & 0.119 & 0.436 & 0.030 & 0.049 \\
\hline M & 0.465 & 0.085 & 0.173 & 0.119 & 0.054 & 0.081 & 0.248 & 0.045 & & 0.010 & 0.129 & 0.252 \\
\hline $\mathrm{N}$ & 0.144 & 0.240 & 0 & 0.396 & 0.015 & 0.232 & 0.163 & 0.049 & & 0 & 0.183 & 0.099 \\
\hline $\mathrm{O}$ & 0.035 & 0.195 & 0.218 & 0.208 & 0.228 & 0.005 & 0.163 & 0.213 & & 0.193 & 0.059 & 0.089 \\
\hline $\mathrm{P}$ & 0.109 & 0.110 & 0.371 & & 0 & 0.111 & 0 & 0.490 & & & 0 & 0 \\
\hline Q & & 0.005 & 0.045 & 0.010 & & 0.121 & 0.079 & 0.099 & & 0.134 & 0.015 & 0.238 \\
\hline $\mathrm{R}$ & & & & & & 0.147 & 0.203 & 0.005 & 0.020 & 0 & 0.386 & 0 \\
\hline S & & & & & & & 0.005 & & 0.114 & & & \\
\hline $\mathrm{T}$ & & & & & & & & & 0.034 & 0.059 & & \\
\hline $\mathrm{U}$ & & & & & & & & & 0.134 & & & \\
\hline
\end{tabular}


Table 2 - Number of alleles (A), polymorphic information content (PIC), exclusion probabilities (PE) and observed and expected heterozygosity ( $H_{o}$ and $H_{e}$ respectively) of microsatellite markers in a sample of Pantaneiro horses.

\begin{tabular}{lcclrr}
\hline Locus & $\mathrm{A}$ & PIC & \multicolumn{1}{c}{ PE } & $H_{o}$ & $H_{e}$ \\
\hline VHL20 & 9 & 0.8506 & 0.7151 & 0.863 & 0.681 \\
ASB2 & 9 & 0.8253 & 0.6765 & 0.839 & 0.683 \\
HTG10 & 9 & 0.8182 & 0.6602 & 0.833 & 0.677 \\
ASB23 & 8 & 0.8096 & 0.6507 & 0.825 & 0.825 \\
AHT4 & 8 & 0.7885 & 0.616 & 0.806 & 0.641 \\
ASB17 & 11 & 0.7766 & 0.6143 & 0.791 & 0.734 \\
HMS6 & 6 & 0.7442 & 0.549 & 0.765 & 0.544 \\
AHT5 & 7 & 0.7401 & 0.5503 & 0.760 & 0.603 \\
HMS7 & 7 & 0.7363 & 0.534 & 0.759 & 0.599 \\
LEX33 & 7 & 0.7191 & 0.527 & 0.739 & 0.598 \\
HTG4 & 6 & 0.6966 & 0.4996 & 0.717 & 0.548 \\
HMS3 & 7 & 0.6724 & 0.472 & 0.694 & 0.600 \\
\hline
\end{tabular}

since all microsatellites showed PIC values above 0.5 they were all considered informative markers (Botstein et al. 1980).

Ellegren et al. (1992) suggested that at least ten microsatellite loci should be used to achieve maximum exclusion in horses. Marklund et al. (1994) analyzed eight microsatellite loci in paternity testing to reach a combined exclusion probability of 0.96 to 0.99 in different breeds. Our results shows that selected microsatellites have greater power of exclusion given the fact that we could reach a very high level of exclusion using five loci and analyses of more loci increased the combination efficiency.

The use of microsatellite typing for individual identification, parentage control and solving problems of questionable maternity or paternity is a routine procedure within the horse breeding industry in several countries (Binns et al., 1995; Tozaki et al., 2001; Lee and Cho, 2006). Also, the use of DNA markers has shown an extensive capability to

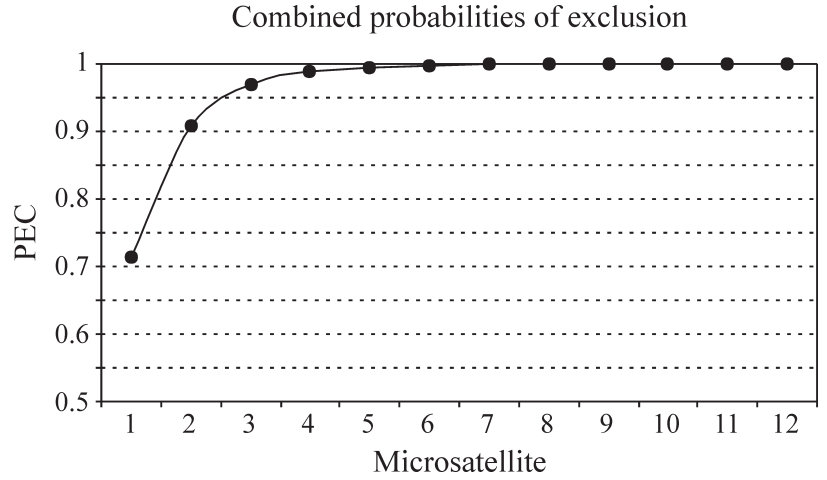

Figure 1 - Combined exclusion as a function of the number of microsatellite loci. $\mathrm{PEC}=$ probability of exclusion.

distinguish between individual horses, and this ability has been used in analyses of reproductive success, kinship and parentage.

The total PE for the 12 microsatellite loci ranged from 0.472 for HMS3 to 0.7151 for VHL20 (Table 2), with the VHL20, ASB2, HTG10 and ASB23 microsatellites showing PE values greater than 0.65 and the HMS3 loci not exceeding 0.5 . Our results shows that our selected microsatellites have greater power of exclusion given the fact we could reach a very high level of exclusion with only five loci (Figure 1).

The results of the genealogy control tests are shown in Table 3. In our study, 101 horses were qualified by the compatibility of 12 markers according to Mendelian laws using DNA typing for parentage verification. However, 1 foal did not inherit alleles from the registered sire (6 incompatible markers) and 2 foals did not inherit alleles from the registered dam and were excluded by the incompatibility of 4 markers for one of these foals and 7 markers for the other foal. Using direct comparison of the genetic formulas we found other possible dams and progenitors with compatible genetic formula. Our result was in agreement with previous studies that microsatellite DNA typing could be useful for

Table 3 - Pantaneiro horse parentage testing example showing three cases tested using 12 microsatellite loci and the comparison of alleles. Values in bold indicate allele incompatibility.

\begin{tabular}{|c|c|c|c|c|c|c|c|c|c|c|c|c|c|}
\hline \multirow[b]{2}{*}{ Cases } & \multicolumn{13}{|c|}{ Microsatellite loci and alleles } \\
\hline & VHL20 & HTG4 & AHT4 & HMS7 & ASB2 & ASB17 & AHT5 & HMS6 & ASB23 & HTG10 & HMS3 & LEX33 & Result \\
\hline \multicolumn{14}{|l|}{ Case 1} \\
\hline Dam & LQ & LP & $\mathrm{HO}$ & $\mathrm{LN}$ & IQ & HR & KK & OP & IS & $\mathbf{L L}$ & IP & LQ & \\
\hline Foal & NN & LN & MO & LL & LQ & NN & KK & MP & $\mathbf{J L}$ & NO & IQ & $\mathrm{KL}$ & Exclusion \\
\hline \multicolumn{14}{|l|}{ Case 2} \\
\hline Dam & IP & KK & $\mathrm{HH}$ & $\mathbf{L P}$ & MN & NR & MN & $\mathbf{L L}$ & $\mathbf{J L}$ & $\mathbf{R R}$ & OP & LL & \\
\hline Foal & NN & MO & HK & NO & KO & IR & $\mathrm{KN}$ & MQ & IS & NN & PP & LL & Exclusion \\
\hline \multicolumn{14}{|l|}{ Case 3} \\
\hline Sire & NQ & NO & $\mathrm{KO}$ & NO & KO & IR & NN & MP & JS & KN & $\mathrm{OP}$ & GL & \\
\hline Foal & KQ & MP & HI & $\mathbf{L L}$ & QQ & MR & NO & KO & SS & MR & OP & OQ & Exclusion \\
\hline
\end{tabular}


parentage testing (Usha et al., 1995; Tozaki et al., 2001; Marklund et al., 1994).

The 12 microsatellite marker system is theoretically considered to be highly useful for parentage checking in the Pantaneiro horse in Brazil. The EGPTSC suggests nine microsatellite markers (AHT4, AHT5, ASB2, HMS3, HMS6, HMS7, HTG4, HTG10 and VHL20) as a minimum international standard microsatellite marker system, as well as additional markers (ASB17, ASB23, LEX33) to be typed for horse parentage testing. Furthermore, the EGPTSC has recommended that parentage testing should rely on exclusion based on the incompatibility of two or more markers, because an exclusion based on a single marker may involve an element of uncertainty. Higher PE values may solve problems of some genetic markers in a population and is often used with molecular markers in pedigree verification. All possibilities should be tried to obtain additional information to support a decision for such an exclusion, including tests for additional markers or mutation analysis (Binns et al., 1995).

Our data showed failure in the individual identification system and confirmed interest in using genetic markers in this system. The markers detected mistakes in identification and allowed, depending on the case, to solve genealogy problems. Identification and genealogical control of the Pantaneiro horse nucleus using a panel of genetic markers would be of great importance for the preservation program being applied to this breed.

\section{Acknowledgments}

The authors thank the Laboratorio de Genética Molecular del Servicio de Cría Caballar y Remonta de Córdoba for support during the genotyping analysis, Embrapa Pantanal for sample collection from the Pantaneiro horse. The first author thanks to Brazilian National Research Council (CNPq) for a research fellowship.

\section{References}

Binns MM, Holmes NG, Holliman A and Scott AM (1995) The identification of polymorphic microsatellite loci in the horse and their use in thoroughbred parentage testing. Br Vet $\mathrm{J}$ 151:9-15

Botstein D, White RL, Skolmick H and Davis RW (1980) Construction of a genetic linkage map in man using restriction fragment length polymorphism. Am J Anim Genet 32:314331.

Bowling AT, Eggleston-Stott ML, Byrns G, Clark RS, Dileanis S and Wictum E (1997) Validation of microsatellite markers for routine horse parentage testing. Anim Genet 28:247-252.

Breen M, Lindgren G, Binns MM, Norma J, Irvin Z, Bell K, Sandberg K and Ellegren H (1997) Genetical and physical assignments of equine microsatellites - First integration of anchored markers in horse genome mapping. Mamm Genome 8:267-273.

Cho GJ and Cho BW (2004) Microsatellite DNA typing using 16 markers for parentage verification of the Korean native horse. Asian-Aust J Anim Sci 17:750-754.

Dowdall RC (1982) Criando Criollos. Hemisferio Sur SA, Buenos Aires, 409 pp.

Ellegren H, Johansson M, Sandberg K and Andersson L (1992) Cloning of highly polymorphic microsatellites in horse. Anim Genet 23:133-142.

Guérin G, Bertand M and Amigues Y (1994) Characterisation of seven new horse microsatellites: HMS1, HMS2, HMS3, HMS5, HMS6, HMS7, HMS8. Anim Genet 25:62.

Huguet E, Canacedo A and Gené M (1988) Introducción a la Investigación Biológica de la Paternidad. PPU, Barcelona, $206 \mathrm{pp}$.

Kawasaki ES (1990) Sample preparation from blood, cells and other fluids. In: Innis MA, Gelfand DH, Sninsky JJ and White TJ (eds) PCR Protocols: A Guide to Methods and Applications. Academic Press, New York, pp 146-152.

Lear TL, Brandon R and Bell K (1999) Physical mapping of ten equine dinucleotide repeat microsatellites. Anim Genet 30:235.

Lee SY and Cho GJ (2006) Parentage testing of thoroughbred horse in Korea using microsatellite DNA typing. J Vet Sci 7:63-67.

Marklund S, Ellegren H, Eriksson S, Sandberg K and Andersson, L (1994) Parentage testing and linkage analysis in the horse using a set of highly polymorphic microsatellites. Anim Genet 25:19-23.

Miller MP (1997) Tools for Population Genetic Analyses (TFPGA) Versión 1.3: A Windows program for the analysis of alloenzyme and molecular population genetic data. Computer software distributed by author.

Shiue Y-L, Bickel LA, Caetano AR, Millon LV, Clark RS, Eggleston ML, Michelmore R, Bailey E, Guérin G, Godard $\mathrm{S}$ et al. (1999) A synteny map of the horse genome comprised of 240 microsatellite and RAPD markers. Anim Genet 30:1-9.

Tozaki T, Kakoi H, Mashima S, Hirota KI, Hasegawa T, Ishida N, Miura N, Choi-Miura NH and Tomita M (2001) Population study and validation of paternity testing for Thoroughbred horses by 15 microsatellite loci. J Vet Med Sci 63:11911197.

Tautz D, Trick M and Dover G (1986) Crypitic simplicity in DNA is a major source of genetic variation. Nature 322:652-656.

Usha AP, Simpson SP and Williams JL (1995) Probability of random sire exclusion using microsatellite markers for parentage verification. Anim Genet 26:155-161.

Van Haeringen H, Bowling AT, Stott ML, Lenstra JA and Zwaagstra KA (1994) A highly polymorphic horse microsatellite locus: VHL20. Anim Genet 25:207.

Associate Editor: Pedro Franklin Barbosa 